(1316)

\title{
畭燥ばくてりおふゅーじゅ， 長期保存二關入儿研究
}

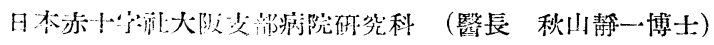

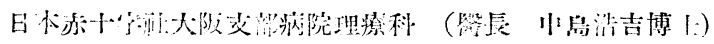

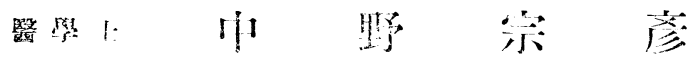

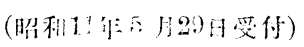

\section{【㐫 容 抄 錄】}

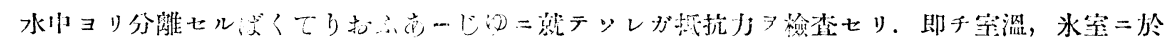

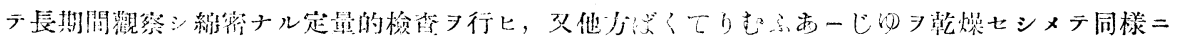

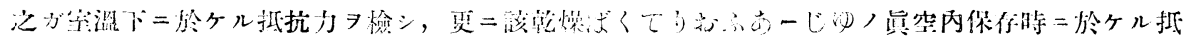

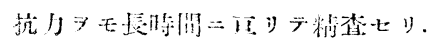

\section{目次}

繀司

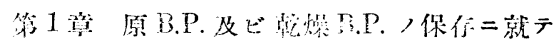

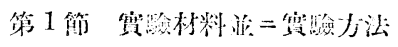

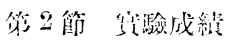

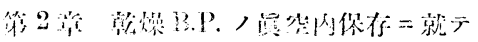

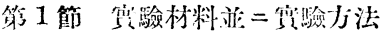

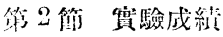

第 3 等 總 括

拄裂文献

䋨

言

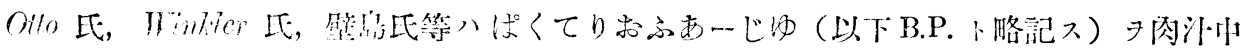

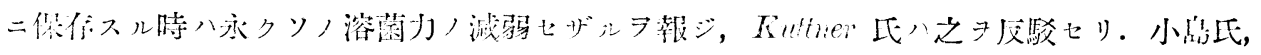

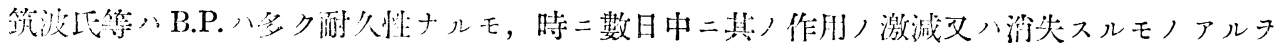

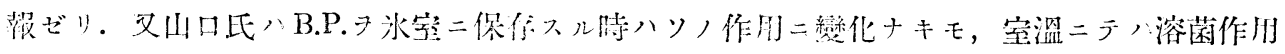

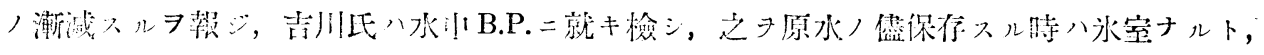

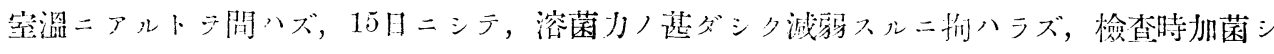

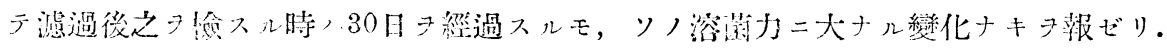

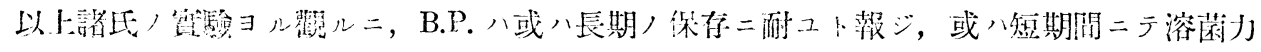

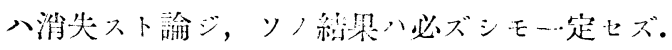

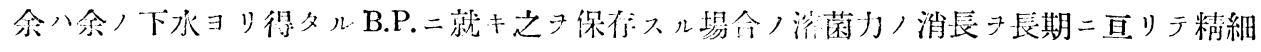

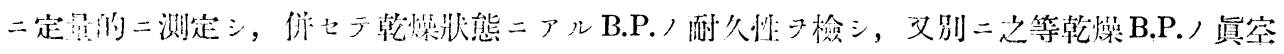




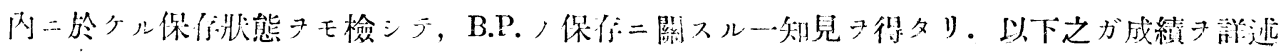
スル所アラントス。

第 1 章 原 B.P. \&ビ乹燥 B.P.ノ保停二就テ

\section{第 1 筑 䁈驗材料该二䁈驗方法}

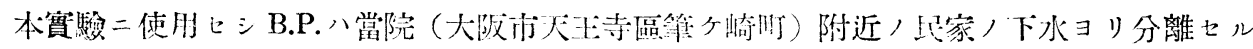

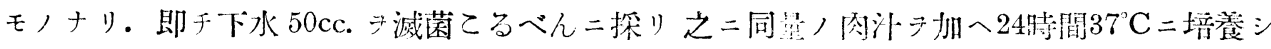

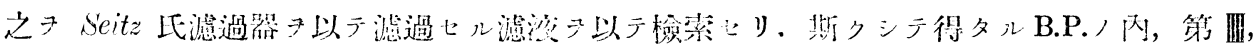

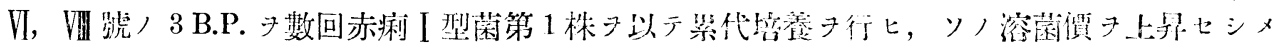
タル後々フ帺䁩二供セリ。

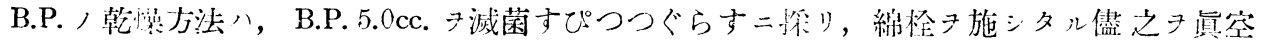

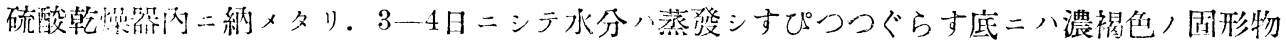

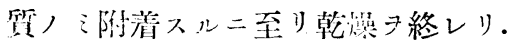

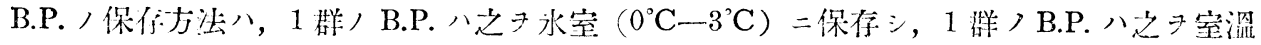

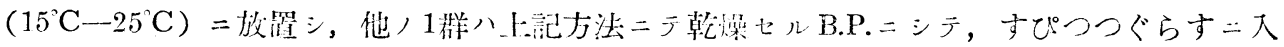

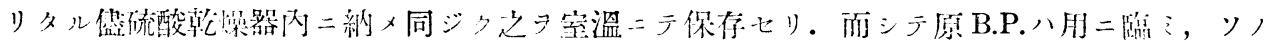

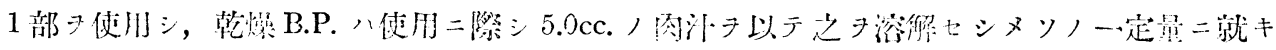
檢七り。

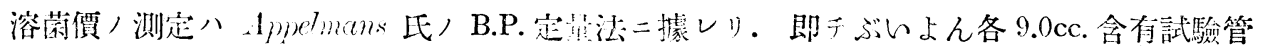

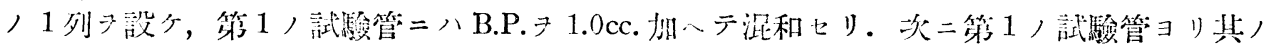

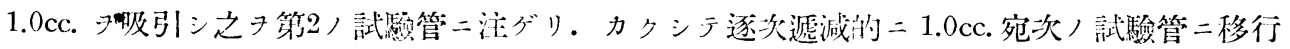

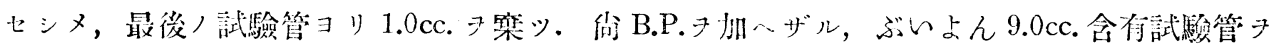
對想ト七リ。

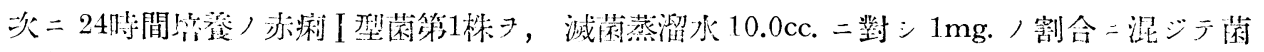

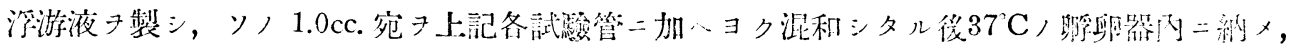

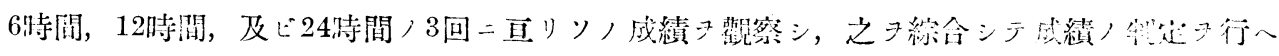
リ。

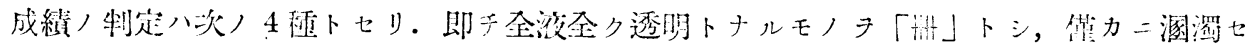
ルモ殆ンド透明キルモノタ「州」トシ，透鹏部ト溷摆部が相生バスルガ如キモノタ「H」ト

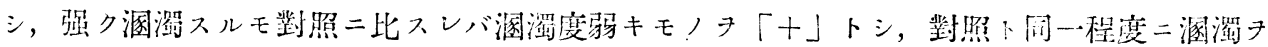
是シタルモノタ「一」トセり。

第 2 節實㱦成 績 
BP. 及ビ乾燥B.P.ノ溶菌價ハ15月每二6ร月閒之キ测定七リ。之等ノ實驗成續八第1ー3表 記載ノ如シ。

第 1 表 (下水 顺B.P.).

\begin{tabular}{|c|c|c|c|c|c|c|c|c|c|c|c|c|c|c|c|c|c|c|c|c|c|}
\hline $\begin{array}{l}\text { 保存 } \\
\text { 期闬 }\end{array}$ & 1 & & 日 & 1 & ケ & 月 & 2 & ケ & 月 & 3 & ケ & 月 & & ケ & 月 & 5 & ケ & 月 & 6 & ケ & 月 \\
\hline 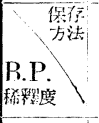 & 氷 & 空 & r & 米 & 窒 & 乾 & 头 & 空 & 影 & 氷 & 帘 & 歡 & 水 & 室 & 乾 & 水 & 空 & 筑 & 冰 & 空 & 鄅 \\
\hline $10^{-1}$ & Htt & $\mathrm{HHH}$ & $H$ & $\mathrm{HH}$ & Hit & HA & Hitt & HAt & Hit & HHt & HH: & $H+i$ & $\mathrm{HH}$ & $H$ & HH & $H i$ & - & Hith & $t+H$ & - & HH \\
\hline $10-2$ & H! & $H_{i}$ & HII & $\mathrm{HH}$ & $H$ & $\mathrm{Hir}$ & $\mathrm{HHH}$ & $\mathrm{HH}$ & Hit & $H i t$ & HHt & $H H$ & $H i_{i}^{i}$ & HH & $H$ & HH & - & Hit & Ht & - & $\mathrm{HH}$ \\
\hline $10^{-3}$ & HH & Htr & HIt & $H+H$ & HH & Hit & 詶 & $H 4$ & H: & Hit & thit & $H 1$ & 洲 & $4:$ & HH & + & - & $H 4$ & + & - & HH \\
\hline $10^{-4}$ & $\mathrm{HH}$ & HWH & HI! & H & Hit & Hit & $\mathrm{HHH}$ & $H+H$ & tht & th! & Hit & $H+1$ & Hiti & $H t$ & !tti & + & - & in & - & - & Hiti \\
\hline $10^{-5}$ & Hit & $\mathrm{m}$ & $H$ & $\mathrm{HAH}$ & tri & tht & $H+1$ & $H$ & $H H$ & th & $H$ & $H+H$ & HH & $H$ & $H+$ & - & - & $H H$ & - & - & H: \\
\hline $10-6$ & HH & HH & Hit & H: & Hit & thit & $H !$ & $\mathrm{HH}$ & 洲 & $H 4$ & H & Hit & 44 & + & 蜘 & - & - & !H! & - & - & thH \\
\hline $10-7$ & HH & $H+$ & H & $H$ & $\mathrm{HH}$ & $\mathrm{HH}$ & Hit & $\mathrm{HH}$ & HH & 出 & + & $4+4$ & Hit: & - & $H H$ & - & - & $\mathrm{H}+\mathrm{H}$ & - & - & - HH \\
\hline $10-8$ & $H H$ & HWH & $\mathrm{HH}$ & $H$ & Hit & H H & iHH & $H H$ & HHt & 计 & + & Hit & $4 n$ & - & $H$ & - & - & $H H$ & - & - & $4+4$ \\
\hline $10^{-9}$ & HWH & HW & $\mathrm{HH}$ & Hit & HH & HHi & $\mathrm{HHH}$ & + & $4+$ & $\mathrm{HH}$ & - & HH & titt & - & tit: & - & - & 洲! & - & $\dot{-}$ & $\mathrm{HHi}$ \\
\hline $10^{-10}$ & HH & HIH & $\mathrm{HH}$ & $H+H$ & $H$ & HII & int & + & $H !$ & HAH & $\cdots$ & thit & Hit & - & Itti & - & - & tit & - & - & HH \\
\hline $10^{-11}$ & $\mathrm{HHi}$ & +4 & $\mathrm{HH}$ & He & + & HH & $H H$ & - & Hit & $\mathrm{HH}$ & - & Hitt & Hit & - & HAH & - & - & $\mathrm{HHI}$ & - & - & 喌 \\
\hline $10^{-12}$ & HH & $H+1$ & $H$ & $H+$ & + & $H$ & $H+$ & - & $H$ & tit & - & it & + & - & $+t-$ & - & - & $H$ & - & - & $H$ \\
\hline $10^{-13}$ & HIt & $H+H$ & $H$ & $H$ & - & $H$ & $H$ & - & + & $H$ & - & $H$ & + & - & $H$ & - & - & $H$ & - & - & $H$ \\
\hline $10^{-14}$ & $H$ & $H$ & + & + & - & + & + & - & + & + & - & + & - & - & + & - & - & + & - & - & + \\
\hline 對照 & - & - & - & - & - & - & - & - & - & - & - & - & - & - & - & - & - & - & - & - & . \\
\hline
\end{tabular}

\section{第 2 表 (下水 VI B.P.).}

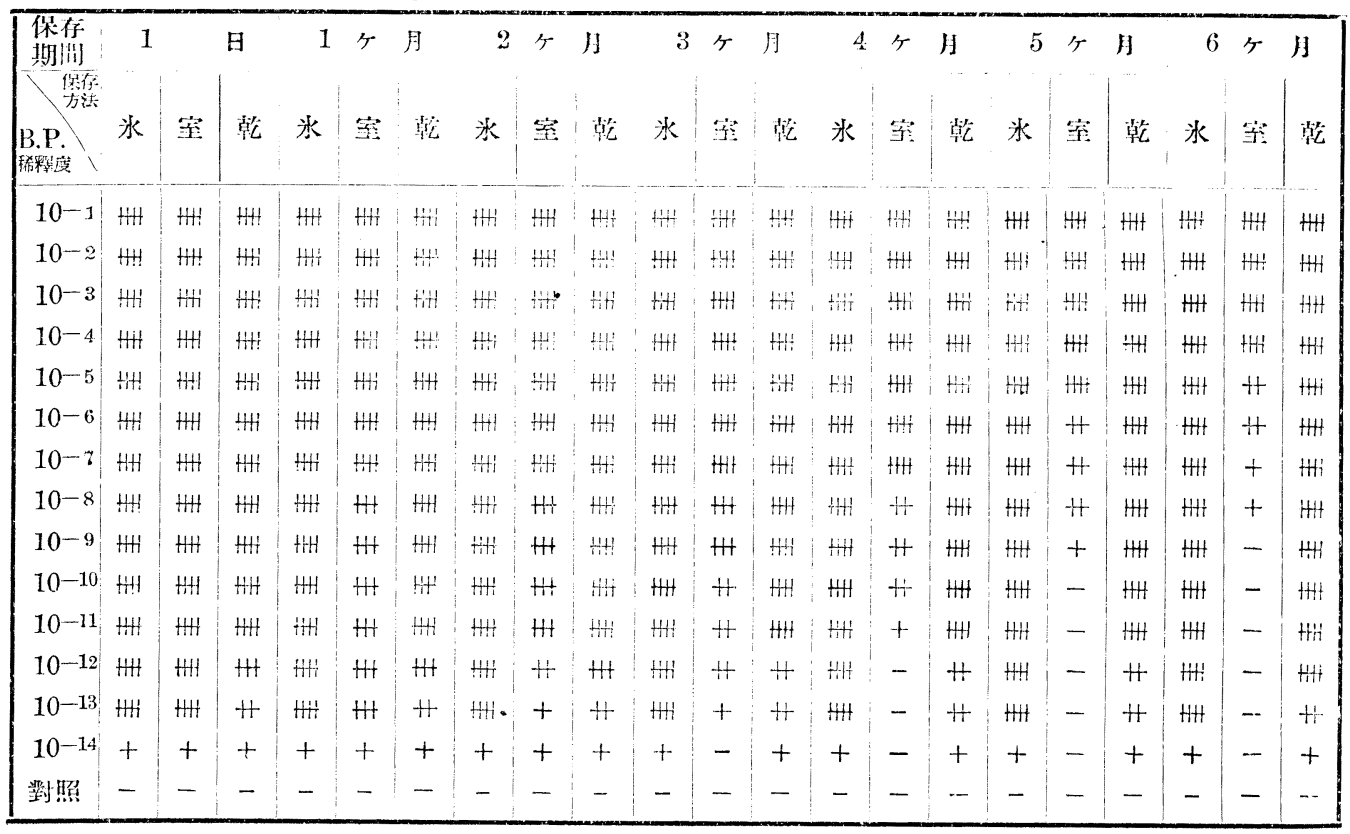


中野宗这述

第 3 表 (下水 Vill B.P.).

\begin{tabular}{|c|c|c|c|c|c|c|c|c|c|c|c|c|c|c|c|c|c|c|c|c|c|}
\hline 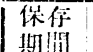 & 1 & & 日 & 1 & ケ & H & 2 & ケ & 月 & 3 & ケ & 月 & 4 & ケ & H & 5 & 4 & 月 & 6 & T & 月 \\
\hline B.P. & 氷 & 空 & 飘 & 氷 & 空 & 政 & 涾 & 穿 & r & 米 & 空 & 㢣 & 水 & 空 & 萨 & 氷 & 尝 & 乾 & 水 & 窒 & 乾 \\
\hline $10^{-1}$ & HH & $H+H$ & iHA & H州 & HH & HiH & HH & $\mathrm{iHH}$ & H⿻川⿲丶丶丶一世 & Hent & HWH & Hitt & H+H & HH! & $H H$ & HIH & $H+!$ & HHH & HHH & $\mathrm{HH}$ & $\mathrm{HH}$ \\
\hline $10-2$ & HH & HH & 洲 & HH & $\mathrm{HH}$ & $H+H$ & HW & Hit' & $H+H^{\prime}$ & Hith & HiH & HII & HII & HH! & itH & IHH & $H 4$ & H⿻川 & HH & H\# & $H$ \\
\hline $10-3$ & H & $\mathrm{HHH}$ & $\mathrm{HWH}$ & HII & HWH & $t+H$ & $\mathrm{H}+\mathrm{H}$ & HWH & $\mathrm{HH}$ & $\mathrm{HWH}$ & $\mathrm{H}+\mathrm{H}$ & Hit & H! & $\mathrm{HH}$ & Hil & HH & titt & Hiti & $H H$ & HiH & $H H$ \\
\hline $10-4$ & HW & HW & $H+m$ & $\mathrm{HH}$ & $\mathrm{H}+\mathrm{H}$ & HiH & $\mathrm{HH}$ & HWH & $H H$ & $\mathrm{H}+\mathrm{H}$ & $\mathrm{HH}$ & $H$ & $\mathrm{HH}$ & HH & $\mathrm{HHH}$ & HWH & 洲 & H⿻川 & Hit & HH & HW \\
\hline $10^{-5}$ & $H$ & $\mathrm{HHH}$ & $H W$ & HHH & $H+t$ & $H H$ & $\mathrm{HH}$ & $\mathrm{HHH}$ & HW & $\mathrm{HHH}$ & Hit & HH & HAl & Ht & $\mathrm{HH}$ & $\mathrm{HH}$ & HH & $\mathrm{HH}$ & $\mathrm{HH}$ & H & HW \\
\hline $10^{-6}$ & $\mathrm{HH}$ & $\mathrm{HH}$ & $H$ & $\mathrm{HH}$ & $\mathrm{HH}$ & Hith & $\mathrm{H}+\mathrm{H}$ & $H$ & HWH & : & $H$ & HH & $\mathrm{HH}$ & $H$ & 䜣! & $\mathrm{HH}$ & + & HWH & $H$ & + & HH \\
\hline $10-7$ & H & HH & H1 & $\mathrm{HH}$ & $H$ & HH & $\mathrm{HH}$ & + & $t r i t$ & $H$ & $T$ & Hit & $\mathrm{Ht}$ & + & $\mathrm{HH}$ & HH & + & HW & $\mathrm{HH}$ & + & $H$ \\
\hline $10-8$ & HII & HH & HH & HWH & + & HH & $H$ & + & $H+H$ & $\mathrm{HH}$ & + & $H$ & $H$ & + & $H$ & HH & - & Ht & $H$ & $\therefore$ & H \\
\hline $10^{-9}$ & H⿻ & $\mathrm{HH}$ & HH & $\mathrm{Ht}$ & + & $\mathrm{HH}$ & HH & + & H & $\mathrm{HH}$ & + & HH & + & + & $\mathrm{Ht}$ & + & - & $H$ & + & - & $H$ \\
\hline $10-10$ & $H$ & $\mathrm{HH}$ & H & $\mathrm{HH}$ & + & $\mathrm{HH}$ & $H$ & - & $\mathrm{HH}$ & $H$ & - & $H$ & + & - & $H$ & + & - & $H$ & + & - & $H$ \\
\hline $10^{-11}$ & H & H & $H$ & $H$ & - & $H$ & $H$ & - & $H$ & + & - & + & - & - & + & - & - & + & - & - & + \\
\hline $10^{-12}$ & $H$ & $H$ & + & $H$ & - & + & + & - & + & + & - & + & - & - & + & - & - & + & - & - & + \\
\hline $10^{-13}$ & $H$ & $H^{-}$ & + & + & - & + & + & - & - & - & - & - & - & - & - & - & - & - & - & - & - \\
\hline $10^{-14}$ & + & + & - & + & - & $\cdot$ & + & - & - & - & - & - & - & - & - & - & - & - & - & - & - \\
\hline 粼治 & - & - & - & - & - & - & - & - & - & - & - & - & - & - & - & - & - & - & - & - & - \\
\hline
\end{tabular}

劣表中, 水八水室保你, 室八室溫保倞ノB.P.ノ示入溶菌㵋ニシテ，乾八乾燥 B.P.ノ溶菌價 チ示ス毛ノナリ。

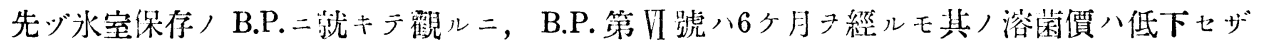

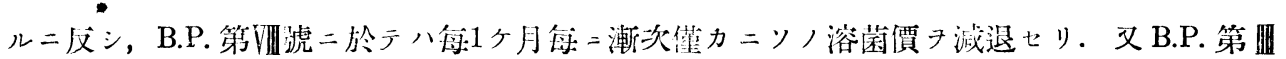
號ハ4ケ月目迄八認么べキ溶菌價ノ減退ナキモ，5 月月目ヨリ著明二溶菌價キ低下゙セリ．

次二室溫保佔ノモノ二於テハ, 水室保倞ノモノ二比シソノ溶菌價ノ減退ハ大ナリ。即于

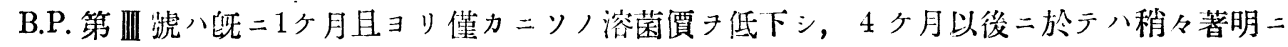

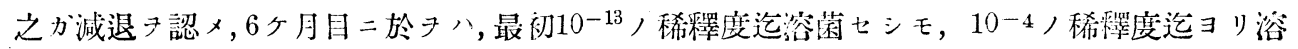

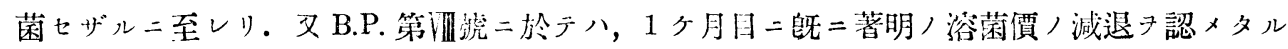

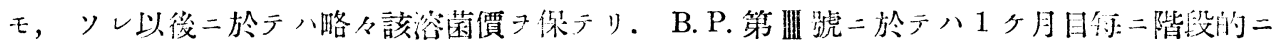
溶菌賈

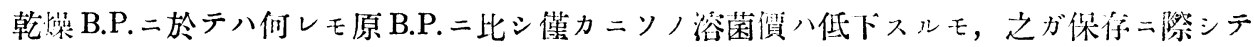

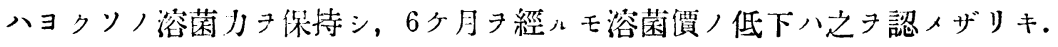

第 2 意 乾燥 B.P. /县空內保存二就テ

第 1 節 實驗材料並二賔驗方法 
本實驗 二使用七シ B.P.八前章記載ノモノト全ク同一ナリ。

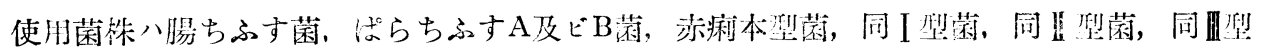

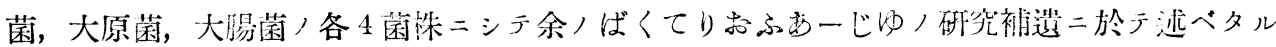
菌株卜同一ナリ。

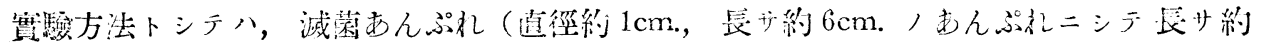

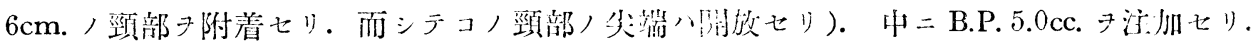

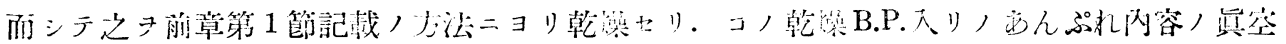
方法八次, 如 シ.

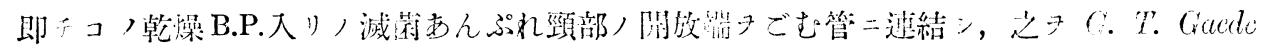

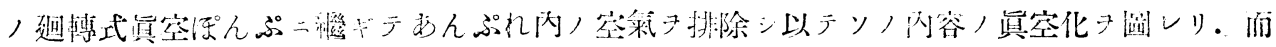

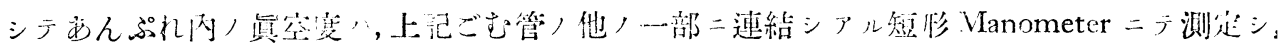

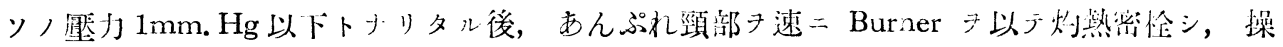
作ヨ完了セリ.

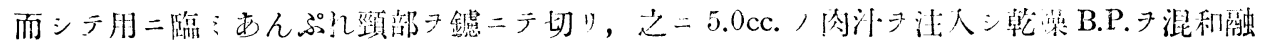

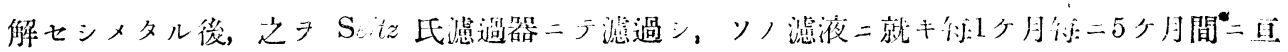
リ本泛法二テ檢セり。

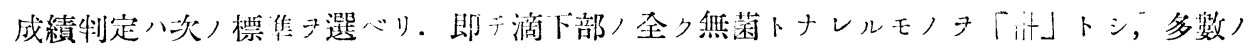

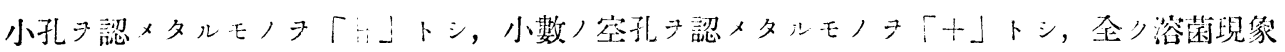

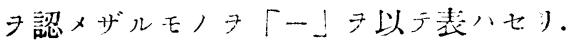

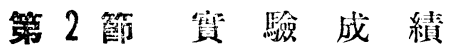

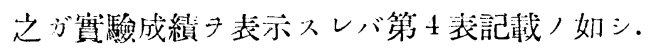

第 4 表

\begin{tabular}{|c|c|c|c|c|c|c|c|c|c|c|c|c|c|c|c|c|c|c|}
\hline B.P. >種類 & & 第 & & & 㔠 & & & 第 & & & 昽 & & & 4 & & & 沼虎 & \\
\hline $\begin{array}{l}\text { 你存具问 } \\
\text { 菌 株 }\end{array}$ & $\begin{array}{l}\text { 龁 } \\
\text { 照 }\end{array}$ & $\begin{array}{l}1 \\
\text { ケ } \\
\text { 月 }\end{array}$ & $\begin{array}{l}2 \\
\text { ケ } \\
H\end{array}$ & $\begin{array}{l}3 \\
\text { ケ } \\
1\end{array}$ & $\begin{array}{l}4 \\
\text { ケ } \\
H\end{array}$ & $\begin{array}{l}5 \\
\text { ケ } \\
\mathrm{A}\end{array}$ & $\begin{array}{l}\text { y } \\
\text { II }\end{array}$ & $\begin{array}{l}1 \\
\text { ケ } \\
H\end{array}$ & $\begin{array}{l}2 \\
5 \\
13\end{array}$ & $\begin{array}{l}3 \\
3 \\
H\end{array}$ & $\begin{array}{l}4 \\
\text { ケ } \\
\text { 月 }\end{array}$ & $\begin{array}{l}5 \\
5 \\
\text { 月 }\end{array}$ & $\begin{array}{l}\text { 啐 } \\
\text { !!品 }\end{array}$ & $\begin{array}{l}1 \\
\text { צ } \\
\text { II }\end{array}$ & $\begin{array}{l}2 \\
5 \\
\text { 月 }\end{array}$ & $\begin{array}{l}3 \\
3 \\
\text { 月 }\end{array}$ & $\begin{array}{l}4 \\
\text { r } \\
\text { H }\end{array}$ & $\begin{array}{l}5 \\
5 \\
10\end{array}$ \\
\hline$\|_{3} \quad N r .1$ & - & - & - & - & - & - & - & - & - & - & - & - & - & $\cdots$ & - & - & - & - \\
\hline b $\quad N r .2$ & - & - & - & - & - & - & $H$ & $H$ & $H$ & + & - & + & - & - & - & - & - & - \\
\hline$\stackrel{5}{\$} N r .3$ & - & - & - & - & - & - & - & - & - & - & - & - & $\ldots$ & $\cdots$ & - & - & - & - \\
\hline 菌 $\quad N r \cdot 4$ & tt & $H$ & + & H & $H$ & $H$ & - & - & - & - & - & - & - & - & - & - & - & - \\
\hline ばA $N r .1$ & - & - & - & - & - & - & - & - & - & - & - & - & - & - & - & - & -- & - \\
\hline $5 \quad N r .2$ & - & - & - & - & - & - & - & - & - & - & - & - & - & - & - & - & - & - \\
\hline $\begin{array}{lll}\text { b } & N r .3\end{array}$ & - & - & - & - & - & - & - & - & - & - & - & - & - & - & - & - & - & - \\
\hline 与菌 Nr. 4 & - & - & - & - & - & - & - & - & - & - & - & - & - & - & - & - & - & - \\
\hline
\end{tabular}




\begin{tabular}{|c|c|c|c|c|c|c|c|c|c|c|c|c|c|c|c|c|c|c|}
\hline B.P.八积颣 & & 第 & & & 號 & & & 第 & & & 㸡 & & & 第 & VI & & 㨿 & \\
\hline 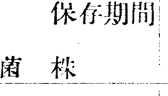 & $\begin{array}{l}\text { 對 } \\
\text { !品 }\end{array}$ & $\begin{array}{l}1 \\
5 \\
H\end{array}$ & $\begin{array}{l}2 \\
5 \\
1\end{array}$ & $\begin{array}{l}3 \\
5 \\
\text { 月 }\end{array}$ & $\begin{array}{l}4 \\
5 \\
月 \\
\end{array}$ & $\begin{array}{l}5 \\
\text { ケ } \\
\text { 月 }\end{array}$ & 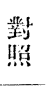 & $\begin{array}{l}1 \\
5 \\
\text { 月 }\end{array}$ & $\begin{array}{l}2 \\
5 \\
\text { 月 } \\
\end{array}$ & $\begin{array}{l}3 \\
5 \\
H\end{array}$ & $\begin{array}{l}4 \\
5 \\
\text { 月 }\end{array}$ & $\begin{array}{l}5 \\
\text { 年 } \\
\text { H }\end{array}$ & $\begin{array}{l}\text { 傼 } \\
\text { 照 }\end{array}$ & $\begin{array}{l}1 \\
r \\
\text { 月 }\end{array}$ & $\begin{array}{l}2 \\
5 \\
H\end{array}$ & $\begin{array}{l}3 \\
5 \\
13\end{array}$ & $\begin{array}{l}4 \\
5 \\
\text { 月 }\end{array}$ & $\begin{array}{l}5 \\
5 \\
1 \\
\end{array}$ \\
\hline $\begin{array}{ll}\text { ばB } & N r .1 \\
己 & N r .2 \\
\text { ち } & N r .3 \\
\text { 号 } & N r .3 \\
\text { す菌 } & N r .4\end{array}$ & $\begin{array}{l}- \\
- \\
+ \\
-\end{array}$ & $\begin{array}{l}- \\
- \\
+ \\
-\end{array}$ & $\begin{array}{l}- \\
- \\
+ \\
-\end{array}$ & $\begin{array}{l}- \\
- \\
- \\
-\end{array}$ & $\begin{array}{l}- \\
- \\
+ \\
-\end{array}$ & $\begin{array}{l}- \\
- \\
- \\
-\end{array}$ & $\begin{array}{l}- \\
- \\
- \\
-\end{array}$ & \begin{tabular}{l|}
- \\
- \\
- \\
-
\end{tabular} & $\begin{array}{l}- \\
- \\
- \\
-\end{array}$ & $\begin{array}{l}- \\
- \\
- \\
-\end{array}$ & $\begin{array}{l}- \\
-\end{array}$ & $\begin{array}{l}- \\
- \\
- \\
-\end{array}$ & $\begin{array}{l}- \\
- \\
- \\
-\end{array}$ & $\begin{array}{l}- \\
- \\
- \\
-\end{array}$ & \begin{tabular}{l|}
- \\
- \\
- \\
-
\end{tabular} & $\begin{array}{l}- \\
- \\
- \\
-\end{array}$ & $\begin{array}{l}- \\
- \\
- \\
-\end{array}$ & $\begin{array}{l}- \\
- \\
- \\
-\end{array}$ \\
\hline $\begin{array}{ll}\text { 赤 } & N r .1 \\
\text { 僦 } & N r .2 \\
\text { 本 } & N r .3 \\
\text { 型 } & N r .3 r .4 \\
\end{array}$ & $\begin{array}{l}+ \\
+ \\
+ \\
H\end{array}$ & $\begin{array}{l}+ \\
+ \\
+ \\
+\end{array}$ & $\begin{array}{l}+ \\
+ \\
H \\
H\end{array}$ & $\begin{array}{l}H \\
+ \\
H \\
H\end{array}$ & $\begin{array}{l}+ \\
+ \\
+ \\
H\end{array}$ & $\begin{array}{l}+ \\
+ \\
+ \\
+\end{array}$ & $\begin{array}{l}T \\
+ \\
+ \\
-\end{array}$ & $\begin{array}{l}+ \\
+ \\
+ \\
-\end{array}$ & $\begin{array}{l}- \\
+ \\
+ \\
-\end{array}$ & $\begin{array}{l}+ \\
+ \\
-\end{array}$ & $\begin{array}{l}H \\
+ \\
-\end{array}$ & $\begin{array}{l}+ \\
+ \\
+ \\
-\end{array}$ & $\begin{array}{l}+ \\
- \\
- \\
-\end{array}$ & $\begin{array}{l}+ \\
- \\
- \\
-\end{array}$ & \begin{tabular}{l|}
+ \\
- \\
- \\
-
\end{tabular} & $\begin{array}{l}+ \\
- \\
- \\
-\end{array}$ & $\begin{array}{l}+ \\
- \\
- \\
-\end{array}$ & $\begin{array}{l}- \\
- \\
- \\
-\end{array}$ \\
\hline 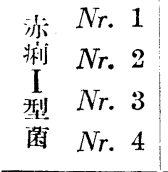 & $\begin{array}{l}H \\
H \\
H \\
H\end{array}$ & $\begin{array}{l}H+ \\
H \\
H \\
H\end{array}$ & $\begin{array}{l}H+ \\
H \\
H \\
H\end{array}$ & $\begin{array}{l}H+ \\
H \\
H \\
H\end{array}$ & $\begin{array}{l}H+ \\
H \\
H \\
H\end{array}$ & $\begin{array}{l}H \\
H+ \\
H \\
H\end{array}$ & $\begin{array}{l}\text { H } \\
H \\
H+ \\
+\end{array}$ & $\begin{array}{l}\text { Ht } \\
H \\
H \\
+\end{array}$ & $\begin{array}{l}\text { H } \\
+ \\
+ \\
+\end{array}$ & $\begin{array}{l}\text { H } \\
+ \\
H \\
+\end{array}$ & $\begin{array}{l}H \\
H \\
H \\
-\end{array}$ & $\begin{array}{l}H \\
H \\
H \\
-\end{array}$ & $\begin{array}{l}+i t \\
H \\
- \\
-\end{array}$ & $\begin{array}{l}H \\
H \\
- \\
-\end{array}$ & $\begin{array}{l}H \\
H \\
- \\
-\end{array}$ & $\begin{array}{l}\text { Ht } \\
+ \\
- \\
-\end{array}$ & $\begin{array}{l}H \\
H \\
- \\
-\end{array}$ & $\begin{array}{l}H+ \\
H \\
- \\
-\end{array}$ \\
\hline $\begin{array}{cl}\text { 赫 } & N r .1 \\
\text { 犁 } & N r .2 \\
\text { II } & N r .3 \\
\text { 型 } & N r .3 \\
\text { 菂 } & N r .4 \\
\end{array}$ & $\begin{array}{l}H+ \\
H \\
H \\
H\end{array}$ & $\begin{array}{l}H+ \\
H \\
H \\
H\end{array}$ & $\begin{array}{l}H \\
H \\
H \\
H\end{array}$ & $\begin{array}{l}H \\
H \\
H \\
H\end{array}$ & $\begin{array}{l}H \\
H \\
H \\
H\end{array}$ & $\begin{array}{l}H+ \\
H+ \\
H \\
H\end{array}$ & $\begin{array}{l}H \\
H \\
H \\
-\end{array}$ & $\begin{array}{l}H \\
H \\
H \\
-\end{array}$ & $\begin{array}{l}H \\
H \\
H \\
-\end{array}$ & $\begin{array}{l}H \\
H \\
H \\
-\end{array}$ & $\begin{array}{l}H \\
H \\
-\end{array}$ & $\begin{array}{l}H \\
H \\
H \\
-\end{array}$ & $\begin{array}{l}- \\
+ \\
+ \\
-\end{array}$ & $\begin{array}{l}- \\
+ \\
+ \\
-\end{array}$ & $\begin{array}{l}- \\
+ \\
+ \\
-\end{array}$ & $\begin{array}{l}- \\
+ \\
+ \\
-\end{array}$ & $\begin{array}{l}- \\
- \\
+ \\
-\end{array}$ & $\begin{array}{l}- \\
+ \\
+ \\
-\end{array}$ \\
\hline 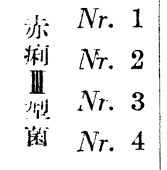 & $\begin{array}{l}H+ \\
H \\
H \\
H\end{array}$ & $\begin{array}{l}H+ \\
H \\
H \\
H\end{array}$ & $\begin{array}{l}H \\
H \\
H \\
H\end{array}$ & $\begin{array}{l}H \\
H \\
H \\
H\end{array}$ & $\begin{array}{l}H \\
H \\
H \\
H\end{array}$ & $\begin{array}{l}H \\
H \\
H \\
H\end{array}$ & $\begin{array}{l}- \\
H \\
H \\
-\end{array}$ & \begin{tabular}{l|}
- \\
$H$ \\
$H$ \\
-
\end{tabular} & $\begin{array}{l}- \\
H+ \\
H \\
-\end{array}$ & $\begin{array}{l}- \\
H \\
H \\
-\end{array}$ & $\begin{array}{l}- \\
H \\
H+ \\
-\end{array}$ & $\begin{array}{l}- \\
H+ \\
H \\
-\end{array}$ & $\begin{array}{l}- \\
+ \\
H+ \\
-\end{array}$ & $\begin{array}{l}- \\
+ \\
H \\
-\end{array}$ & $\begin{array}{l}- \\
+ \\
+H \\
-\end{array}$ & $\begin{array}{l}- \\
+ \\
+ \\
-\end{array}$ & $\begin{array}{l}- \\
+ \\
H+ \\
-\end{array}$ & $\begin{array}{l}- \\
+ \\
H+ \\
-\end{array}$ \\
\hline $\begin{array}{ll}\text { 大 } & N r .1 \\
& N r .2 \\
\text { 原 } & N r .3 \\
& \text { 菌 } \\
& N r .4\end{array}$ & $\begin{array}{l}+ \\
+ \\
- \\
-\end{array}$ & $\begin{array}{l}\text { H+ } \\
+ \\
- \\
-\end{array}$ & $\begin{array}{l}+ \\
+ \\
- \\
-\end{array}$ & $\begin{array}{l}+ \\
+ \\
- \\
-\end{array}$ & $\begin{array}{l}H \\
+ \\
- \\
-\end{array}$ & $\begin{array}{l}H \\
- \\
- \\
-\end{array}$ & $\begin{array}{l}- \\
H \\
H \\
-\end{array}$ & $\begin{array}{l}- \\
H \\
H\end{array}$ & $\begin{array}{l}- \\
H+ \\
H+ \\
-\end{array}$ & $\begin{array}{l}H \\
H \\
-\end{array}$ & $\begin{array}{l}- \\
H \\
H \\
-\end{array}$ & $\begin{array}{l}- \\
H \\
H \\
-\end{array}$ & $\begin{array}{l}H+ \\
H \\
- \\
-\end{array}$ & $\begin{array}{l}\text { H } \\
- \\
-\end{array}$ & $\begin{array}{l}H+ \\
H \\
- \\
-\end{array}$ & $\begin{array}{l}\text { Hit } \\
H \\
- \\
-\end{array}$ & $\begin{array}{l}H \\
H \\
- \\
-\end{array}$ & $\begin{array}{l}H \\
H \\
- \\
-\end{array}$ \\
\hline 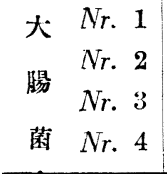 & $\begin{array}{l}- \\
- \\
+ \\
+\end{array}$ & $\begin{array}{l}- \\
- \\
+ \\
+\end{array}$ & $\begin{array}{l}- \\
- \\
+ \\
H\end{array}$ & $\begin{array}{l}- \\
- \\
+ \\
+\end{array}$ & $\begin{array}{l}- \\
- \\
H\end{array}$ & $\begin{array}{l}- \\
- \\
+ \\
+\end{array}$ & $\begin{array}{l}- \\
- \\
+ \\
-\end{array}$ & $\begin{array}{l}- \\
- \\
+ \\
-\end{array}$ & $\begin{array}{l}- \\
+ \\
-\end{array}$ & $\begin{array}{l}- \\
- \\
- \\
-\end{array}$ & $\begin{array}{l}- \\
- \\
+ \\
-\end{array}$ & $\begin{array}{l}- \\
- \\
- \\
-\end{array}$ & $\begin{array}{l}- \\
H+ \\
- \\
-\end{array}$ & $\begin{array}{l}- \\
H+ \\
- \\
-\end{array}$ & $\begin{array}{l}- \\
+ \\
- \\
-\end{array}$ & $\begin{array}{l}- \\
+H \\
- \\
-\end{array}$ & $\begin{array}{l}- \\
+ \\
- \\
-\end{array}$ & $\begin{array}{l}- \\
H \\
- \\
-\end{array}$ \\
\hline 溶街 & 22 & 22 & 22 & 21 & 21 & 20 & 16 & 16 & 15 & 15 & 14 & 15 & 10 & 10 & 10 & 10 & 9 & 9 \\
\hline
\end{tabular}

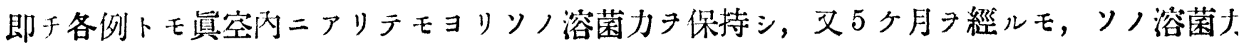
及ビ浴菌範圍ハ殆ンド全ク變化テ蒙ラザリキ.

\section{第 3 童 總}

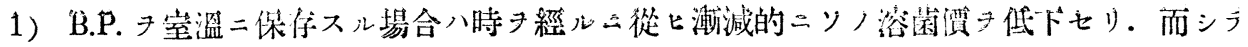
6ケ月ヨ經ル時ハ2例二於テハソノ浴菌賈ハ牛減シ，1例ニ於テハ既二5ケ月ニシテソノ溶菌才。 
キ沙失セリ。

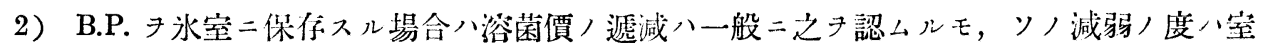
溫保你ノモノ二比シ弱シ。文6 ケ月キ經ルモ全ク浴菌價ノ低下タ認メザルモノモ你入。

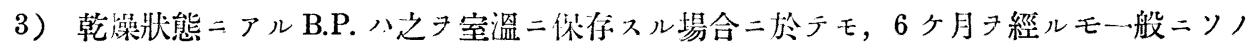
浴菌價ハ減弱 來サズ.

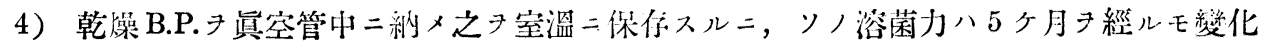
ク認メズ.

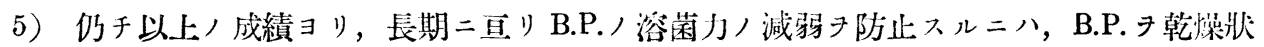

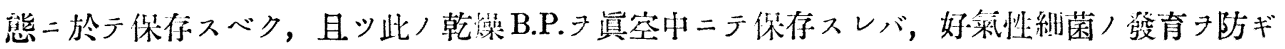
永ク B.P. 比較的純粹二保存シ得べキ 高調セントス.

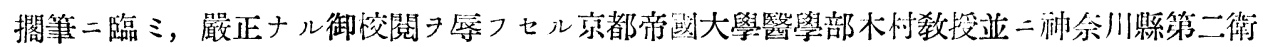

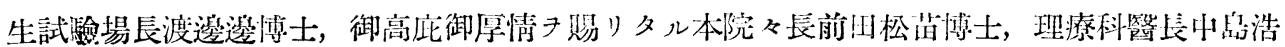
吉博士，不斷八御指導习煩ハシタル硎究科醫長秋山靜一博士二衷心ヨリノ謝意ヨ表入。

\section{主 要 女 献}

1) Kabeshima, T., C. r. Soc. biol., 1920, t. $83 . \quad$ 2) Kuttner, A. G., Proc. Soc. Exp. Boil., 1921，18. 3) 小島克巳, 日本微生物學雜誌, 筙 18 行, 大正 13 年.

4) Otto, R. u. Winkler, W. F., Deut. med. Wchschr. 1922, Bd. $48 . \quad$ 5) 筑波

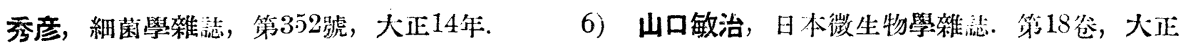
13年. 7) 吉川吉次, 日本微生物學雜誌, 第 27 忩, 昭和 8 年. 